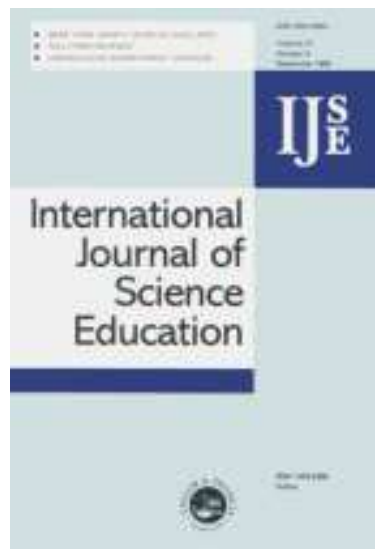

\title{
Evaluation of a Design Principle for Fostering Students' Epistemological View on Models and Modelling using Authentic Practices as Contexts for Learning in Chemistry Education
}

\begin{tabular}{|r|l|}
\hline Journal: & International Journal of Science Education \\
\hline Manuscript ID: & TSED-2010-0064.R2 \\
\hline Manuscript Type: & Research Paper \\
\hline Keywords: & Authentic practices, Models and modelling, Context-based \\
\hline Keywords (user): & \multicolumn{2}{|l}{} \\
\hline
\end{tabular}

\section{SCHOLARONE ${ }^{\mathrm{m}}$ \\ Manuscripts}


Evaluation of a Design Principle for Fostering Students' Epistemological View on Models and Modelling using Authentic Practices as Contexts for Learning in Chemistry Education

\begin{abstract}
Science education should foster students' epistemological view on models and modelling consistent with formal epistemology in science and technology practices. This paper reports the application of a curriculum unit in the classroom using an authentic chemical practice, 'Modelling drinking water treatment', as the context for learning. An authentic practice is defined as professionals working on an issue guided by common motives and purposes, according to a similar type of procedure and applying relevant knowledge. The epistemology on models and modelling in the practice was analysed and anchored in the curriculum unit. The knowledge involved was captured in a design principle 'content modelling'. A design principle provides heuristic guidelines to reach the intended pedagogic effects in the classroom. Throughout the field tests, research data were collected by means of classroom observations, interviews, audio-taped discussions, completed worksheets and written questionnaires. Students were able to evaluate the advanced model features of goodness of fit and reliability, and, to a lesser extent, validity. However, reflection on the modelling approach applied can be improved. The findings were used to reconsider the current completion of the design principle 'content modelling'. This study contributes to the acquisition of a knowledge base concerning the use of authentic practices as contexts for learning in chemistry education as well as in science education in a broader sense.
\end{abstract}




\section{Introduction}

One of the central goals of science education is to promote model-based reasoning in students (Clement, 2000) . Students should understand that models are primarily a representation of ideas about phenomena and can be rejected, replaced or modified in order to fit new (empirical) data. In addition, students should become acquainted with advanced model features, like reliability and validity, and with different modelling approaches and procedures.

Before discussing further, we define our use of the terms model and the process of modelling in this study. We use the term model as some structured representation, including symbolic elements, of the essential characteristics of an idea, object, event process or a system. (Gilbert and Boulter, 2000; Schwarz and White, 2005). We use the term modelling for the process used in much of modern science and technology that involves (a) embodying key aspects of theory and data into a model, (b) evaluating that model using advanced features such as reliability and validity and (c) revising that model to accommodate new theoretical ideas or empirical findings (Schwarz and White, 2005). In this paper we concentrate on models and modelling in the domain of chemical engineering sciences. In this paper we also use the term 'technology' to denote engineering approaches.

Many modelling tasks given to students in school do not give rise to deeper understanding related to models and modelling (Erduran and Duschl, 2004). As reported in the literature, many students have difficulties grasping the essence of models and modelling (Grosslight, Unger, Jay, \& Smith, 1991). Our central argument in this paper is that the epistemology of many school modelling tasks is antithetical to the epistemology of modelling in science and technology. In the current paper we use 
$\underline{\text { the term 'epistemology' to denote the situational nature of knowledge, its continuous }}$ development and active interference with the world and its subjects and objects. Above argument has important implications for the design of modelling tasks conducted in schools. Science education involves more than learning theories and models devised by others, it also involves developing appreciation for the usefulness of the epistemology and assumptions of the discipline (Enfield, Smith, \& Grueber, 2007). It has been claimed that this might be realised if students are engaged in modelling processes similar as those used in real science or technology settings (Edelson, 1998; Sadler, 2009). In this paper we refer to such settings as authentic modelling practices.

Authentic modelling practices are characterised by a community of workers working according to shared purposes, common motives and standardised procedures using relevant knowledge, tools and attitudes (Author-2, Author, Author, \& Author-3, 2006; Author-1, Author-2, Author, \& Author-3, 2008). Authentic modelling practices can be adapted into contexts for learning. If this is done so that students become meaningfully engaged, the assumption is that students come to construct, test and evaluate models guided by similar motives and convictions as in the authentic practice. In addition, students will come to learn and use the epistemic notions consistent with the formal epistemology of the particular practice at hand. This vision of learning of is underpinned by the activity theory in education (Engestroem, 1987; $\underline{\text { Leont'ev, 1978). }}$

In a previous study we adapted the authentic practice 'Modelling drinking water treatment' into a context for learning and applied the resulting curriculum unit in classroom_(Author-1, 2010). In the present study, we evaluate and reflect on the learning outcomes related to models and modelling. We aim to elaborate the potential 
of the approach outlined above and reflect on strategies applied in the teachinglearning process to focus students on the epistemology of models and modelling.

\section{Theoretical framework}

In this section we first summarise some major epistemological views regarding models and modelling in science and technology. Secondly, we focus on the epistemology of models and modelling in the authentic practice 'Modelling drinking water treatment'. Thirdly, we outline the major characteristics of the context for learning, including a description of the instructional strategies applied in the teachinglearning process to focus students on the epistemology of models and modelling.

Epistemology of models and modelling in science and technology

Epistemology refers to one's basic beliefs about what knowledge is in science and $\underline{\text { technology, including their respective activities (Sensevy, Tiberghien, Santini, Laubé, }}$ \& Griggs, 2008). Although the science-technology relation is still under debate, we regard both domains as complementary to each other. Between both domains exists a $\underline{\text { weak and reciprocal interaction. }}$

For the science domain, the epistemologist Giere (1988) suggest a 'naturalistic' explanation based on how science_is actually done in laboratories, offices, and so on. Giere treats scientific theories as a structured family of models, and distinguishes a perspective of discovery, in which new theories and models are created and elaborated, and a perspective of justification, where theories and models are tested against empirical evidence. In the latter, two interests are identified, namely 'evidence-based' and 'value-loaded'. The evidence-based interest values theories and models on the basis of evidence. In contrast, the value-loaded interest leads scientists to prefer one theory or model over another independently of considerations of 
evidence. One should keep in mind that the evidence-based and value-loaded interests are both valuable and do not exclude each other. In numerous occasions in science the evidence for preferring one theory or model over another purely on epistemic grounds is scant or poor, in which case value-loaded interests decide the issue. In this respect, value-loaded interests play a dual role. They structure theory and model choices within the perspective of justification under conditions of epistemic uncertainty, and they structure practice in the perspective of discovery. Value-loaded interests generate a kind of dynamics of scientific practice. Scientists do not just choose theories and models, they work on and with them.

Lenk (2003) argues that Giere's combination of scientific models and their relation to real systems needs to be extended with a action-theoretical interpretation to account for the insoluble interconnection between knowledge, experimenting and action. Such view also covers technological approaches, since technology can be seen as an complex interaction between understanding and acting, requiring conceptual, procedural and methodological knowledge, expertise, skills and information (Ankiewicz and De Swardt, 2006). The type of understanding differs from the analytical understanding endorsed in science (Cajas, 1999). As a consequence, more $\underline{\text { concrete and pragmatic approaches are used to clarify key aspects of the object under }}$ examination. As for modelling, roughly two approaches can be distinguished: an empirical and mechanistic one. The mechanistic modelling approach starts from theoretical ideas about the object at hand, while the empirical modelling approach starts from experiment. The choice which modelling approach to follow is guided by epistemic notions such as design, failures, constraints of reality (e.g. kind of materials, $\underline{\text { costs, engineering standards), trade-offs, unintended consequences and negotiations. }}$ 
The above view on the modelling activity in science and technology corresponds with the characteristics given by the epistemologist Hacking (1983/2005). The major points are:

- Theories are not easy to define.

- Observations are not necessarily theory driven. There have been important observations in the history of science and technology which have included no theoretical assumptions.

- Theory and experiments cannot be directly articulated. There is an 'enormously wide ranging intermediate activity best called model-building'.

- The activity of model-building consists of two processes; one starting from theory, which makes the theory more concrete or visible, and one from experiment, which makes this experiment more abstract.

In the present study we unravelled the epistemology of models and modelling by taking an actual authentic practice as point of departure, that is the practice 'Modelling drinking water treatment'. In the next section we give an overview of this practice, with emphasis on the epistemology regarding models and modelling (Author-1 et al., 2008).

Epistemology of models and modelling in the authentic practice 'Modelling drinking $\underline{\text { water treatment' }}$

The treatment of drinking water, and the modelling thereof, is an ongoing matter of concern in many countries, since the quality of drinking water is an important area within the field of public health. Different kinds of contaminants, such as organic compounds and micro-organisms, need to be removed to produce safe drinking water. Several treatment methods are available for this purpose, such as sand filtration and activated carbon filtration. With growing pressures on water treatment, there is now a 
greater need to optimise water works, whether to increase throughput, reduce operational costs, or minimise capital expenditure (Rietveld and Dudley, 2006).

Although drinking water treatment has a long history, the mathematical analysis of treatment processes is still young. Within this practice, many models are data driven, for example, that for coagulation/flocculation treatment. Other treatment processes, such as disinfection, filtration and activated carbon filtration, have been widely studied and the models have a sound basis. Two modelling approaches can be distinguished, namely mechanistic and empirical (or 'black box'). Mechanistic models strive to understand and mathematically describe the mechanics underlying the processes occurring in a given system. Empirical models are simpler and are often obtained by fitting mathematical equations to a set of experimental data. Even though a mechanistic model is preferred, an empirical model is in many cases inevitable, especially when dealing with very complex processes or if the theoretical knowledge is simply lacking. In addition, empirical models are cheap and easily constructed compared to mechanistic models, and are equally powerful in describing process behaviour in response to external alterations, e.g., changes in process variables. Both modelling approaches are conceptualised in Figure 1.

\section{INSERT FIGURE 1 ABOUT HERE}

In an empirical model there is limited information from inside included in the model. One tries to establish a relation between input and output, based on outside information alone._In a mechanistic model information from inside is included, and consists of an argued assemblage of variables, including fit parameters to calibrate the model on empirical data. In short, the major epistemic notions guiding the modelling approach are: 
1. Purpose and/or function of the model;

2. Empirical vs. mechanistic modelling approach, e.g., the available theoretical knowledge regarding the treatment process and its complexity, taken as the number of effecting process variables;

\section{Modelling procedure;}

4. Model features goodness of fit, reliability and validity as criteria for evaluation.

$\underline{\text { In the following section we describe how these four epistemic notions are concretised }}$ and incorporated in the context for learning.

Authentic practice 'Modelling drinking water treatment' as a context for learning

The authentic practice 'Modelling drinking water treatment' comprised the modelling of multiple treatment processes, numerous substances and quality parameters. For use as a context for learning, we decided to focus, or 'zoom in', on one particular treatment step and quality parameter, namely the removal of turbidity by coagulation/flocculation (Author-1, Author-2, Author, \& Author-3, 2009). The unit of measure of turbidity is the nephelometric turbidity unit (NTU). The turbidity of

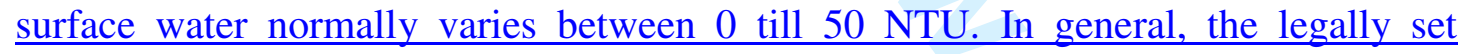
maximum allowed turbidity for drinking water is about 4 NTU. The main reason for focussing on turbidity removal by coagulation \& flocculation is the availability of small-scale laboratory experiments suitable for the school environment (Author-1, 2010). Turbidity is caused by suspended matter, such as clay particles and colloids. The coagulation/flocculation treatment is affected by a variety of process variables, such as type and dose of coagulants and flocculants, starting turbidity, acidity $(p H)$, salt concentration, mixing effects and temperature. The purpose of the modelling is to be able to predict the end turbidity as a function of the 'raw' water quality and process $\underline{\text { conditions (epistemic notion 1). An empirical modelling approach (epistemic notion }}$ 


\section{INSERT FIGURE 2 ABOUT HERE}

The modelling procedure (epistemic notion 3) consists of three major stages (Author$\underline{1,2010):}$

I. Identify major process variables, based on chemistry underlying coagulation/flocculation mechanisms;

II. Conduct experiments under controlled conditions:

- Measure the end turbidity (turbidity ${ }_{\text {out }}$ ) as function of the process variables; dose coagulant, starting turbidity (turbidity in) and temperature. In each series, only one process variable is changed while the other two are held constant;

- Present the experimental data in scatter plots;

III. Perform regression:

- Select those process variables with significant correlation;

- Conduct single regression: fit linear and non-linear (power) regression models on the data;

○ Conduct multiple regression: fit additive and multiplicative models on the data: 
- Multiple linear regression model (additive model, in which process variables are assumed not to interact with each other): Turbidity $_{\text {out }}=a+b_{1}$ Turbidity $_{\text {in }}+b_{2}$ Dose_coagulant $+b_{3}$ Temperature

- Multiple power regression model (multiplicative model, in which interaction between process variable is taken into account):

$$
\text { Turbidity }_{\text {out }}=a\left(\text { Turbidity }_{\text {in }}^{b_{1}}\right)\left(\text { Dose_coagulant }^{b_{2}}\right)\left(\text { Temperature }^{b_{3}}\right) .
$$

The regression models are evaluated on the following features (epistemic notion 4):

○ Goodness of fit: indicated by the value of $R^{2}$. Theoretically, $R^{2}$ can reach the maximum value of 1 , denoting a perfect fit. However, all values $>0.8$ are qualified as a good fit. A notable aspect is that the goodness of fit becomes more significant the more measurements are available;

- Reliability: depending on the number and accuracy of the gathered experimental data, to be judged by the (team of) researcher(s);

- Validity: the tested range of the process variables, e.g. $\mathrm{X}_{1}<$ turbidity $_{\text {in }}(\mathrm{NTU})<$ $\mathrm{X}_{2}, \mathrm{Y}_{1}<$ dose coagulant $(\mathrm{mg} / \mathrm{L})<\mathrm{Y}_{2}$ and $\mathrm{Z}_{1}<$ temperature $\left({ }^{\circ} \mathrm{C}\right)<\mathrm{Z}_{2}$.

In conclusion, the applied empirical modelling approach for turbidity removal by coagulation/flocculation can be characterised as 'value-loaded' (complex process, use an additive or multiplicative regression model) within the perspective of justification (models are fitted on empirical data), starting from an experimental point of view (select significant process variables, make the data more abstract). Next, we turn to $\underline{\text { instructional strategies to apply in the teaching-learning process to ensure that }}$ students gain understanding on the epistemic notions as described above.

Strategies to focus students on the epistemology of models and modelling 
We expect that students are aware of the mentioned epistemic notions in a rudimentary sense at the beginning of their learning process. However, students lack the knowledge and experience to give completion to the epistemic notions, and qualitatively describe and discuss them. The challenge is to design a teaching-learning process such that students get clear sight on these notions in the intended way. To achieve this as a pedagogic effect of teaching, there is need for explicit instructional strategies (Chinn and Malhotra, 2002) regarding the details and sequence of the teaching-learning activities.

Design principles are defined as tools providing heuristic guidelines by means of strategy components for realising pedagogic effects in class (Van den Akker, Gravemeijer, McKenny, \& Nieveen, 2006). Design principles link strategy components, e.g., what to do, how precisely, when in the sequence, with what tools and how enacted, pedagogic effects, e.g., students' epistemic notions regarding models and modelling, and arguments, e.g., literature on educational research, empirical findings from previous applications and/or practical considerations. In the adaptation of the authentic practice into a context for learning we distinguished three design principles, labelled context, content modelling and chain of activities (Author$\underline{1,2010)}$. In the current study we focus specifically on the functioning of the design principle of 'content modelling'. The principle of 'content modelling' deals with focussing learners on the essential generic content regarding models and modelling. Figure 3 depicts the design principle 'content modelling'.

\section{INSERT FIGURE 3 ABOUT HERE}

In this study we evaluate to what extent the strategy components lead to the intended pedagogic effects, e.g., students' epistemic notions regarding models and modelling, and reflect on the underpinning arguments. 
Scope and research question

This research study is positioned within the broader perspective of developing and investigating context-based curriculum units in science education. The aim of this study is to contribute to a knowledge base regarding the use of authentic chemical modelling practices as contexts for learning. The present study builds on a previous one, in which the authentic practice 'Modelling drinking water treatment' was selected as suitable context for learning (Author-1 et al., 2009). The selection was based upon criteria students' interest, ownership, familiarity and complexity. The topic of water treatment is well known in Dutch curriculum. In general, students are $\underline{\text { familiar with basics treatment methods (e.g. filtration, adsorption, precipitation, }}$ aeration) and the major concepts involved (e.g. alkalinity, oxidation, contaminants). $\underline{\text { However, students are unfamiliar with the employed mathematical models, as well as }}$ the applied modelling approaches. Currently, the Dutch chemistry (Van Koten, De $\underline{\text { Kruijff, Driessen, Kerkstra, \& Meinema, 2003) and science (KNAW, 2003) curricula }}$ are under revision to make way for new topics, such as modelling. Within this respect, $\underline{\text { the current Dutch developments and this research study can be positioned within the }}$ international trend to implement and investigate context-based approaches (Author-3 and author-2, 2006).

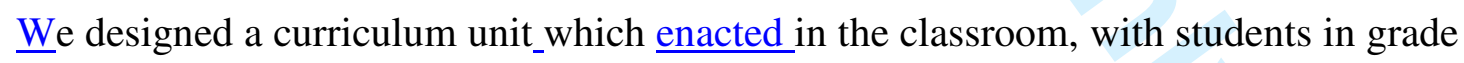
10 and 11 (age 16-17 years), in upper secondary chemistry education. The evaluation was focussed on the functioning of the design principle of 'content modelling'. The central research question addressed here is:

To what extent does the current completion of the design principle of 'content modelling' lead students to acquire the intended insight into epistemology of models and modelling? 
In this section we describe the designed curriculum unit and its application in the classroom, the participants, the data collection and analysis.

\section{$\underline{\text { Design-based research }}$}

Our design-based research approach strongly resembles what Cobb, Confrey, DiSessa, Lehrer, and Schauble (2003) described as 'design experiments' conducted in the classroom. This approach implies the instructional design of a teaching-learning process, accompanied by a set of argued expectations of how the process is expected to take place and why it should operate according to these expectations (Lijnse, 1995). These expectations are based on literature as well as empirical findings in previous research cycles. The teaching-learning process is designed in close cooperation with teachers. The testing of the process takes place in a small-scale case study, with a classroom and its teacher as the unit as analysis (Cobb, Stephan, McClain, \& Gravemeijer, 2001). The findings are used to evaluate the design principle, which might give reasons for a (partial) redesign to be tested in the next research cycle.

\section{$\underline{\text { The curriculum unit }}$}

The curriculum unit consists of five separate learning phases, in which different instructional functions are to be achieved. In Table 1 the broad outline of the curriculum unit is described per learning phase. In Appendix A all the teachinglearning activities are described in detail.

\section{INSERT TABLE 1 ABOUT HERE}

\section{$\underline{\text { Application in the classroom }}$}

The curriculum unit was put into practice at four different schools in the Netherlands in the period from January to June 2008. In two of the schools, the curriculum unit 
was tested in detail with respect to the functioning of the design principle 'content modelling', as case studies. Both of these schools can be characterised as rural schools with few students from ethnic minorities. In total 44 students participated, aged 16-17 years, and in grades 10 and 11 . The curriculum unit compromised eight lessons of 50 minutes, excluding time for private study. The students worked in teams of four persons (11 teams in total). The teachers were well acquainted with the content and pedagogy of the curriculum unit, since they were involved in the process of designing the unit (author-1, 2010).

\section{$\underline{\text { Data collection and analysis }}$}

Given the purpose of this study, the data required were primarily qualitative. The data

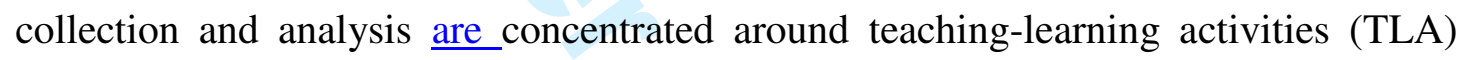
that are regarded as critical as it comes to learning epistemology of models and modelling. The analysis consisted of four stages.

In the first stage, preceding the actual data analysis, two researchers (first and second authors of this paper) developed and agreed upon a frame of reference as a coding scheme. This frame of reference consists of a set of expected students' notions per (cluster of) teaching-learning activities. The teaching-learning activities are the operational construct of the strategy components A to E (see Figure 3), while the students' epistemic notions (intended pedagogic effects) refer to the epistemic notions described in the theoretical framework. In Appendix B the frame of reference is described in detail.

In the second stage, the data were analysed by both of the researchers independently, using this pre-formulated frame of reference. 
In the third stage, all the codes were combined to reveal major trends and findings. Firstly, for each teaching-learning activity per student team, if at least $80 \%$ of the intended pedagogic effects were realised, the corresponding strategy component was deemed fully accomplished. If between 20 and $80 \%$, the valuation was partial, and if between 0 and $20 \%$ it was deemed to have achieved a low level of accomplishment. Secondly, for each strategy component, the judgements of all the student teams were combined. A particular strategy component itself was deemed fully accomplished if it scored high in at least $80 \%$ of all student teams. A strategy component was deemed low, if $80 \%$ of all student teams judged it partly accomplished or less. In case of a score somewhere between these two extremes, the strategy component was deemed partly accomplished. Thirdly, a rater consistency check was conducted by calculating the intraclass correlation coefficient using a two-way mixed effects model (Shrout and Fleiss, 1979).

In the fourth stage, both researchers discussed all the judgments to identify underlying considerations, to unravel students' perspectives and to reflect on the strategy components applied. Finally, all the results were discussed by the complete research team.

The collected data sources are audio-taped conversations of student teams at work, written answers of student teams, interviews with student teams and field notes. Below, we briefly describe each data source and specific analysis procedure.

\section{$\underline{\text { Audio-taped conversations }}$}

While working on teaching-learning activities (TLA) 18-19, the conversations of the student teams at work were audio-taped. Next, the conversations were transcribed 
verbatim, and coded by both researchers independently from an interpretative perspective (Smith, 1995) using the frame of reference.

\section{$\underline{\text { Written answers }}$}

All written answers from the student teams on teaching-learning activities (TLA) 3, 5, 14-16, 18-19, and the factsheets, were coded by two researchers (first and second author) independently using the frame of reference.

\section{$\underline{\text { Interviews }}$}

Each student team was interviewed during or shortly after having accomplished teaching-learning activity (TLA) 3. The interview was semi-structured with the aim being to reveal the students' perspectives on (a) the purpose of the modelling and (b) the modelling procedure to apply (common sense modelling approach). The length of the interview was approximately 10 minutes. The interviews were audio-taped and transcribed verbatim. Next, the interviews were coded by both researchers independently from an interpretative perspective (Smith, 1995) using the frame of reference.

\section{Field notes}

During the complete enactment of the curriculum unit on both schools field notes were made by the first author of this paper. The major purpose of the field notes was to check whether the strategy components, and corresponding teaching-learning activities, were enacted in class with sufficient quality.

\section{Results}

In this section we present the results for each strategy component. At the end, we combine and summarise the findings to answer the research question. The teachinglearning activities were enacted in the classroom as planned. The analysis showed a 
substantial consistency between the raters reflected in the intraclass correlation coefficient of 0.78 .

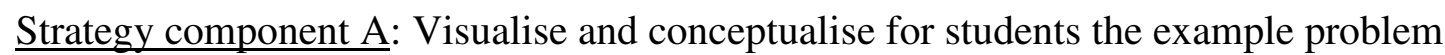
on which they are going to work:

- demonstrate treatment step coagulation/flocculation

- conceptualise the modelling problem as an input-output system

The results show that all teams do notice the process variables of dose coagulant and starting turbidity. Other process variables mentioned were stirring effects, temperature and type of coagulant. All teams recognised the variability of the input. As for the purpose of modelling, ten teams mention the dose coagulant in order to produce clear water. To achieve this, in general, two perspectives are brought to the fore. Six teams propose to concentrate on the relation between the end turbidity and the dose coagulant. On the contrary, five teams suggest focussing explicitly on the process, typified by statements such as 'elucidate what happens on a molecular level'.

Team 7's written answer on teaching-learning activity 3 was:

'Which substances cause the turbidity? What exactly happens? What causes the particles to grow during the stirring phase?'

Ten teams formulated a modelling procedure in response to the plenary demonstration. The majority of the teams (10) focussed on conducting experiments to investigate the variability of external factors, as exemplified below:

Team 4 describes their procedure as follows:

'... try different amounts [dose coagulant], and each time test the residual turbidity and coagulant. If you notice that too much turbidity remains, or too much 
coagulant, then you can determine the situation in which both are the lowest possible. But, since it is variable, you need to test it each time.'

Examples of other mentioned procedural steps are 'study which substances reside in turbidity' and 'find out the best coagulant that leads to coagulation'. In Table 2 the results are summarised, including some general remarks on the functioning of strategy component A.

\section{INSERT TABLE 2 ABOUT HERE}

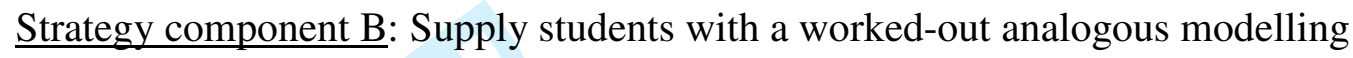
problem as a leading example:

- factsheet 'modelling removal of trichloromethane by activated carbon filtration'

The strategy to bring in a worked-out analogous modelling problem aims to make explicit the meta-modelling knowledge. Ten teams considerably enriched their rudimentary modelling procedure, as formulated in teaching-learning activity 3._Team

9 describes the modelling procedure as follows (for reasons of length, only the main procedural steps, shortened and summarised, are presented):

- Explain the working of the treatment step:

- Schematic representation of treatment step

○ List of process variables

- Process variables:

- Overview of qualitative influence of each process variable

- List of process variables to be researched I kept constant

- Empirical data:

- Plot all gathered data in diagrams

- Draw conclusions from diagrams 
- Correlation \& regression:

- Analyse the diagrams for correlation

- In case of correlation -> conduct regression

○ Determine goodness of fit (value $R^{2}$ )

- Evaluate \& reflect

- Evaluate the mathematical model on reliability

- Recall the purpose of the modelling

$\circ$ Advise on future research.

The advanced model features goodness of fit, reliability and validity, however, were only notified by four teams. In Table 2 the results are summarised, including some general remarks on the functioning of strategy component B.

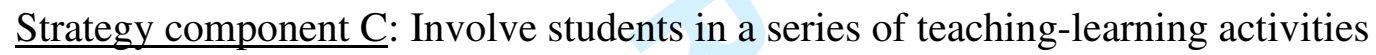
emphasising the nature, characteristics and wording of the model(s) at hand:

- perform experiments;

- construct scatter plots;

- analyse and typify correlations;

- perform single and multiple regression.

Strategy component $\mathrm{C}$ embodies some key aspects regarding modelling. First of all, student teams analyse scatter plots to characterise the type of correlations. Secondly, students fit regression models on the data, both linear and power. Thirdly, students evaluate the regression models on aspects goodness of fit, reliability and validity.

The results show that nine teams were able to draw correct conclusions regarding the correlations based on the scatter plots. The drawing of the scatter plots gave the student teams more insight into the quality of their measurements. The teams 
evaluated each single data point (whether or not falling within the trend) and deleted doubtful measurements. The process variables of dose coagulant and starting turbidity correlated clearly with end turbidity. However, the temperature was less obvious. Six teams concluded that the correlation of the temperature was not significant, and thus could be excluded from further analysis, as typified in Figure 4.

\section{INSERT FIGURE 4 ABOUT HERE}

The majority of the teams (10) did understand the arguments either to leave out or take into account the temperature. For example, here is Team 7 discussing with the teacher the construction of multiple regression model:

S4: ... And if we combine two [process variables], you leave one [process variable] constant, ... and if you combine three [process variables], then you should hold two [process variables] constant [in each series of experiments]. ... So, if we combine three [process variables], then you get the constant values of the other two, and [the model] becomes even less accurate.

Teacher: It [the model] will become less accurate, yes. But, what determines whether or not you take into account the temperature?

S2: How much influence it has.

Teacher: Right!

S3: And how much it differs with [the temperature of] the water taken in [by the drinking water treatment plant].

All teams were able to determine the best line (linear or power) through the scatter plots, including the mathematical formula. While beyond the scope of the exercise, six teams also fitted exponential (and even logarithmic) regression models. These teams extensively used the advanced model feature goodness of fit as an evaluative 
criterion. This fact brought to the fore a fundamental limitation of the empirical modelling approach: the absence of theoretical arguments to navigate to a particular regression model. We will come to this point later on.

In total nine teams succeeded in constructing a multiple regression model. The remaining two teams failed in multiple regression. In valuating the regression models, seven teams used goodness of fit as the decisive criterion. Only four teams explicitly formulated the validity of the constructed regression models. In Table 2 the results are summarised, including some general remarks on the functioning of strategy component $\mathrm{C}$.

$\underline{\text { Strategy component D: }}$ Let students apply the constructed model in a real-world setting:

- calculate the dose of coagulant needed to produce clear water.

Six teams succeeded in calculating the dose coagulant and reflected upon the predictive value of the outcomes. However, the findings reveal that in total ten teams argued about the predictive value of their constructed model. Arguments brought to the fore vary from 'process variables not taken into account' to 'model based on inaccurate measurements'.

Team 5 qualifies the model outcome as follows:

This seems to us a not likely outcome to add $20.6 \mathrm{~g} / \mathrm{L}$ coagulant [to produce water with 1 NTU]. Our model is also not valid in this situation: the $p H$ and temperature are different. This means that our model should be adapted.

Four teams judge their model outcomes as unpredictable, but suggest comparing the outcomes with real-world data, as exemplified by the statement below:

Team 10 reflect on the model outcomes as follows: 
To see whether this [outcome] is real, it should be tested for reliability by conducting this experiment in the real world [not laboratory setting] multiple times. If the amount of added coagulant proves to be around $132 \mathrm{mg} / \mathrm{L}$, then the model outcomes are trustworthy. This, of course, should be tested multiple times under varying conditions ...

The majority of the teams (10) conclude that more (accurate) measurements are needed and that more process variables should be researched to 'make the model fit for every situation'. Four teams argue explicitly for testing the model in a real industrial plant environment, showing that these students are aware of the present state of the model. In Table 2 the results are summarised, including some considerations on the functioning of strategy component $\mathrm{D}$.

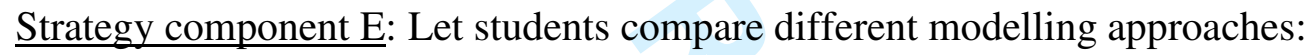

- compare the black-box modelling approach with the mechanistic approach

The findings reveal that ten teams identified the empirical modelling approach and evaluated the approach, as shown by statements below:

The 'black box' approach is quick, easy and also effective as it comes to describing process behaviour. (Team 3)

The 'black box' is just a big experiment, you test process variables, apply regression and construct a formula. A 'mechanistic' approach is much more theoretical regarding which process variables and why. (Team 7)

We did not know exactly what happens during the process. (Team 2)

If high (>0.8) [value $\left.R^{2}\right]$, then alright according to the 'black box' method, but theoretically much remains unclear. (Team 8) 
All teams underline the need for future research, using the advanced model feature goodness of fit, as well as the quality of the measurements, as primary arguments. Four teams explicitly suggest following a more mechanistic approach, as they felt uncomfortable with the empirical modelling approach.

Team 1 suggest future research:

S3: Is there reason for a follow up? You could ...

S4: extensive ...

S3: ... develop a mechanistic model for an exact description of the working and behaviour of the process.

S2: cause ...

S3: well, ... with use of a mechanistic model you can give an exact description.

More or less a follow up of teaching-learning activity 18, all teams again articulate the need to improve the quality of the measurements. Team 4 proposed implementing some kind of JAR test, in which all experiments are done in exactly the same manner.

As for typifying the general problem regarding input-output systems, the answers vary from 'account for variable input, not just one variable', 'apply black box or mechanistic approach' to 'variability of external variables'. On average, the teams emphasise 'variability' as a major problem. Four teams formulated a general procedure for modelling input-output systems, although regression as an essential step was mentioned only once. However, the exact learning gain on meta level remains unclear. It is questionable whether the learning gain is largely absent, or that it is simply not measured. In Table 2 the results are summarised, including some considerations on the functioning of strategy component E.

\section{$\underline{\text { Summary of main findings on the strategy components }}$}


The results for the strategy components A to E are summarised in Table 2. For each strategy component, we also present the major considerations (successful aspects, as well as opportunities and/or possible improvements). As becomes clear, strategy components A (visualise and conceptualise the example problem) and B (supply students with a worked-out analogous problem) function to a sufficient extent. However, strategy component $\mathrm{C}$ (involve students in the nature, characteristics and wording of the models at hand) needs redesign. A main aspect to consider is how to construct a continuous line of teaching-learning sequences from single to multiple regression, such that students arrive at the intended multiple regression model(s). Strategy components D (let students apply the constructed model in a real-world setting) and E (let students compare different modelling approaches), finally, do function as expected and give rise to the intended pedagogic effects, but their functioning can still be improved.

\section{Conclusion and discussion}

The aim of this study was to elaborate knowledge regarding the use of authentic chemical modelling practices as contexts for learning. The knowledge involved was captured in the design principle of 'content modelling' with five strategy components. The principle of 'content modelling' deals with focussing learners on the epistemology of models and modelling. The research question was: to what extent does the current completion of the design principle of 'content modelling' lead students to acquire the intended insight into epistemology of models and modelling?

The results show that four out of five strategy components $(A, B, D, E)$ function sufficiently. Strategy component $\mathrm{C}$, however, requires reconsideration. In this final section we reflect on the functioning of each strategy component, as well as the broader applicability of this design principle for adapting other authentic modelling 
practices into curriculum units. In addition, we formulate implications for future research.

\section{$\underline{\text { Reflections on the functioning of the strategy components }}$}

Based on the findings on the pedagogical effects, it can be concluded that strategy component A (visualise and conceptualise the example problem; epistemic notions 1 and 3; see section 'Theoretical Framework') functions as expected, especially for identifying the process variables, and formulation of the purpose of the modelling as well as a rudimentary modelling procedure. The results show that nearly half of the teams suggest an empirical approach, and the others suggest a mechanistic approach. To further underline the pros and cons of the modelling approach to apply, we add a new strategy component: point out and discuss in class the appropriate modelling approach. A goal of the strategy components A (visualise and conceptualise the example problem) and E (let students compare different modelling approaches) was to conceptualise the coagulation/flocculation treatment step as an example case of an input-output system. This was introduced in strategy component A, and recalled in strategy component E. It was intended that the students would grasp the broader applicability of the empirical modelling approach for complex input-output systems. However, none of the teams took notice of the broader applicability. We are a bit cautious to draw explicit conclusions about this, because the broader applicability can be typified as (a sort of) meta-knowledge, which was hardly made explicit by students (see results on strategy component E). However, the findings suggest that conceptualisation alone does not automatically led students to see the broader applicability. Mentioning other input-output systems that would be recognisable from students' perspective, for which an empirical modelling approach is feasible, might support such understanding. 
It can be concluded that strategy component B (supply students with a worked-out analogous problem; epistemic notions 3 and 4; see section 'Theoretical Framework') works sufficiently for evoking and expressing a modelling procedure. It enriches students' prior modelling knowledge and informs them about modelling activities to conduct. However, the majority of the teams did not note the advanced model features. Such orientation early in the curriculum unit is regarded as essential, because these features are recalled later on in the curriculum unit to evaluate the constructed regression models. We propose to extend the strategy component with measures that will direct students to the advanced model features.

Strategy component $\mathrm{C}$ (involve students in the nature, characteristics and wording of the models at hand; epistemic notion 4; see section 'Theoretical Framework'), however, needs reconsideration. The results show that the proposed gradual formalisation of the observed trends is effective, but demands a careful outlining at the fine granularity of teaching-learning activities. Two major aspects came to the fore:

- The significance of the correlation, e.g., in the present case, the temperature;

- Construction of a continuous line of teaching-learning activities from single to multiple regression.

It seems advisable to emphasise the significance of the correlation in the teachinglearning process, in terms of (1) number of measurements and (2) value of the correlation coefficient. Students need understanding on this matter to be able to judge whether a process variable should be taken into account or not. In the authentic practice, a multiple regression is applied in a straightforward way. However, in the current teaching-learning process the line of reasoning runs via single regression, because students are unfamiliar with regression. It was expected that multiple 
regression is (too) complex for students to learn straight away. The single regression was thus built in as an intermediate stage. From the viewpoint of engineering sciences, this intermediate step is questionable. At this point we see two options:

a. Skip single regression and directly conduct a multiple regression in class. Students immediately fit additive and multiplicative models to the data, using computer program MS Excel; or

b. Assume a linear (or power) correlation between dose coagulant and/or starting turbidity with end turbidity. Explain the assumed correlation as much as possible based on the way the particles interact. Next, conduct single regression, followed by multiple regression, in which additive and multiplicative models are fitted.

Further research is needed to elaborate the pedagogic effects of both options.

Strategy component D (let students apply the constructed model in a real-world setting; epistemic notions 1 and 4; see section 'Theoretical Framework') proved successful in inducing a motive among students to evaluate their model outcomes explicitly. The majority of the teams came up with relevant considerations, especially regarding the number and accuracy of the measurements. This might be an indication that students understand that the quality of the measurements is extremely important in a black-box modelling approach. However, the actual calculation of the dose coagulant using the constructed model needs redesign. In addition, the notion that the model has been constructed in a laboratory setting, and thus needs extensive testing in an industrial environment preceding real usage, can be fostered.

The strategy component E (let students compare different modelling approaches; epistemic notion 2; see section 'Theoretical Framework') proved successful in evaluating the applied modelling approach. Students encountered that science and technology is not a straightforward process, but implies fundamental choices with 
pros and cons. We propose to further strengthen the strategy component with an explicit focus on estimations made, assumptions and neglected variables. In our opinion, through discussing and comparing different modelling approaches earlier in the teaching-learning process, students' views on the epistemology of the applied modelling approach might be fostered.

Summarising all the implications, we come to a slightly altered and generalised filling-in of the design principle 'content modelling', as depicted in Figure 5.

\section{INSERT FIGURE 5 ABOUT HERE}

The results give rise to the incorporation of an extra strategy component, namely to discuss and to point out the appropriate modelling approach early in the teachinglearning process.

\section{$\underline{\text { Reflections on fostering students' epistemological views of models and modelling }}$}

We started this paper with the statement that the epistemology of many school modelling tasks is antithetical to the epistemology of modelling in real science and

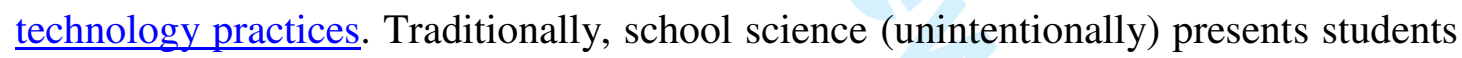
with a straightforward route to the development of new models, leaving out the difficulties and failures inherent in conducting research. We argue that engaging students in authentic practice-based modelling processes might offer a way out. The results obtained in the present study support the arguments and encourage further research on the design challenges. Science curricula, emphasising learning about the nature, purpose and construction of models, has the potential to enable students to develop accurate and productive epistemologies of science and technology (Schwarz and White, 2005). However, as reported in the literature, simply engaging students in developing models is not enough to achieve epistemological sophistication (Carey and 
Smith, 1993). One needs to add a "meta modelling layer", which enables students to develop explicit theories about the nature of models themselves. Sandoval (2005) argues that individuals can rely on multiple epistemologies to interact in different contexts, eliciting students' ideas, challenging those ideas and introducing alternative ideas. In our opinion, this can be realised by engaging students in different authentic modelling practices, in which different epistemological views are employed, such as constructing mechanistic and empirical models. By doing so, we expect that students will gain a richer, more varied perspective on science and technology. In addition, it enables students to gain some insight into socio-scientific values related to authentic practices. However, as might become clear from this study, there are still multiple (major) design challenges in using authentic practices as contexts for learning. The promising results can only be achieved by high quality in the design and enactment of the teaching-learning process.

\section{$\underline{\text { Limitations }}$}

The conclusions of this study are subject to at least three limitations. Firstly, it should be noted that this particular authentic practice was selected after a thorough evaluation (Author-1 et al., 2008). It is important to select authentic modelling practices which, in principle, are feasible for upper secondary chemistry education. Secondly, the design principle 'content modelling' applies to (1) using an authentic practice as the context for learning, (2) the domain of models and modelling, and (3) students in grades 10 and 11 (aged 16-17 years), high school chemistry (upper secondary level). The present filling-in of the principle emerged from the adaptation and enactment of only one authentic practice. The application of this design principle to other authentic modelling practices, either within chemistry or other science domains, needs to be examined. Thirdly, the teachers involved were all well informed about the pedagogy 
of the curriculum unit. Other teachers willing to enact the curriculum unit and to apply this design principle should be confident with the domain specific pedagogy.

$\underline{\text { Implications for future research }}$

Further development of design principles, or equivalent ways for capturing knowledge on educational designs, is important, because it bridges (abstract) theories on learning with the design of concrete teaching-learning activities in class. There is a need for such explicit knowledge, since in many curriculum innovations teachers are designated as the developers of teaching-learning processes. In the next stage of this project we will focus on the broader applicability of the design principle of 'content modelling'. The fact that model-based teaching and learning is widely regarded as central in science education makes it worthwhile to develop further a knowledge base about the use of authentic modelling practices as contexts for learning.

\section{References}

Author-1. (2010).

Author-1, Author-2, Author, \& Author-3. (2008).

Author-1, Author-2, Author, \& Author-3. (2009).

Author-2, Author, Author, \& Author-3. (2006).

Author-3 \& author-2. (2006)

Ankiewicz, P., \& De Swardt, E. (2006). Some Implications of the Philosophy of

Technology for Science, Technology and Society (STS) Studies. International Journal of Technology and Design Education, 16, 117-141.

Cajas, F. (1999). Public understanding of science: using technology to enhance school science in everyday life International Journal of Science Education, 21(7), $\underline{765-773 .}$ 
Carey, S., \& Smith, C. (1993). On Understanding the Nature of Scientific Knowledge. Educational psychologist, 28(3), 235-251.

Chinn, C. A., \& Malhotra, B. A. (2002). Epistemologically Authentic Inquiry in Schools: A Theoretical Framework for Evaluating Inquiry Tasks. Science Education, 86, 175-218.

$\underline{\text { Clement, J. (2000). Model based learning as a key research area for science education. }}$ International Journal of Science Education, 22, 1041-1053.

Cobb, P., Confrey, J., DiSessa, A., Lehrer, R., \& Schauble, L. (2003). Design experiments in educational research. Educational Researcher, 32(1), 9-13.

Cobb, P., Stephan, M., McClain, K., \& Gravemeijer, K. (2001). Participating in classroom mathematical practices. The Journal of the Learning Sciences, $\underline{10(1 \& 2), 113-163 .}$

Edelson, D. C. (1998). Realising authentic science learning through the adaptation of scientific practice. In B. J. Fraser \& K. G. Tobin (Eds.), International Handbook of Science Education (Vol. I, pp. 317-331). Dordrecht: Kluwer.

Enfield, M., Smith, E. L., \& Grueber, D. J. (2007). "A sketch is like a sentence": Curriculum structures that support teaching epistemic practices of science. Science Education, 92(4), 608-630.

Engestroem, Y. (1987). Learning by expanding: An activity-theoretical approach to developmental research. Helsinki: Orienta-Konsultit.

Erduran, S., \& Duschl, R. A. (2004). Interdisciplinary characterizations of models and $\underline{\text { the nature of chemical knowledge in the classroom. Studies in Science }}$ Education, 40, 105-138.

Giere, R. N. (1988). Explaining science. Chicago: The University of Chicago Press. 
Gilbert, J. K., \& Boulter, C. J. (2000). Developing models in science education. Dordrecht: Kluwer Academic Publishers.

Grosslight, L., Unger, C., Jay, E., \& Smith, C. (1991). Understanding models and their use in science: conceptions of middle and high school students and experts. Journal of Research in Science Teaching, 28(9), 799-822.

Hacking, I. (1983/2005). Representing an intervening. Cambridge: University Press Cambridge.

KNAW. (2003). Robuuste profielen in het voortgezet onderwijs /Profiles for secondary science education] Amsterdam: KNAW [Dutch Royal Academic Society].

Lenk, H. (2003). A Reappraisal Regarding "Theories" and "Theoretical Concepts": Towards an Action-Theoretical and Technology-Oriented Philosophy of $\underline{\text { Science and Epistemology. In C. Politis \& W. Schommers (Eds.), Grasping }}$ Reality. An Intertation-Realistic Epistemology (Vol. 5, pp. 72-89). Singapore: World Scientific Publishing.

Leont'ev, A. N. (1978). Activity, consciousness and personality. Englewood Cliffs, New Yersey: Prentice-Hall, Inc.

Lijnse, P. L. (1995). 'Developmental research' as a way to empirically based 'didactical structure of science'. Science Education, 79(2), 189-199.

Rietveld, L. C., \& Dudley, J. (2006). Models for drinking water treatment. Review state-of-the-art (No. 6).

$\underline{\text { Sadler, T. D. (2009). Situated learning in science education: Socio-scientific issues as }}$ contexts for practice. Studies in Science Education, 45, 1-42.

$\underline{\text { Sandoval, W. A. (2005). Understanding students' practical epistemologies and their }}$ influence on learning through inquiry. Science Education, 89, 634-656. 
Schwarz, C. V., \& White, B. Y. (2005). Metamodeling knowledge: Developing students' understanding of scientific modeling Cognition and Instruction, 23(2), 165-205.

Sensevy, G., Tiberghien, A., Santini, J., Laubé, S., \& Griggs, P. (2008). An epistemological approach to modeling: Cases studies and implications for science teaching. Science Education, 92(3), 424-446.

Shrout, P. E., \& Fleiss, J. L. (1979). Intraclass correlations: Uses in assessing rater reliability. Psychological Bulletin, 86(2), 420-428.

Smith, J. A. (1995). Semi-structured interviewing and qualitative analysis. In J. A. Smith, R. Harre \& L. Van Langenhove (Eds.), Rethinking Methods in Psychology. (pp. 9-26). Thousand Oaks: Sage.

Van den Akker, J., Gravemeijer, K., McKenny, S., \& Nieveen, N. (2006). Educational design research. London: Routlegde.

Van Koten, G., De Kruijff, B., Driessen, H. P. W., Kerkstra, A., \& Meinema, H. A. (2003). Building Chemistry. A Blueprint to initiate renewal of the chemistry programme in upper secondary education in the Netherlands (No. VO/2331/D/03-117). Enschede, NL: SLO. 
Appendix A. Overview of the curriculum unit in terms of content and sequence of teaching-learning activities

In this appendix the curriculum unit is described in terms of content and sequence of teaching-learning activities per learning phase.

Phase I: Orientate on the practice

Phase II: Zoom in on an example problem

\begin{tabular}{|c|c|}
\hline $\begin{array}{l}\text { Content related } \\
\text { questions }\end{array}$ & Sequence of teaching-learning activities (TLA) including desired learning outcomes \\
\hline $\begin{array}{l}\text { What constitutes } \\
\text { major steps and } \\
\text { what knowledge is } \\
\text { involved in } \\
\text { modelling the } \\
\text { removal of } \\
\text { turbidity by } \\
\text { coagulation/ } \\
\text { flocculation? }\end{array}$ & 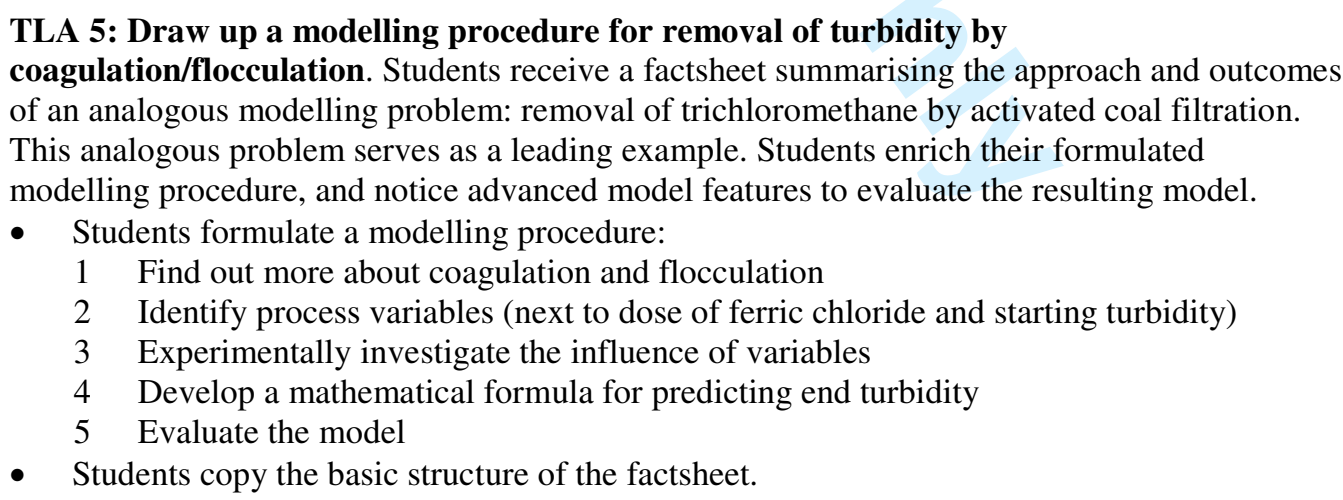 \\
\hline
\end{tabular}


How large is the influence of each process variable?

Which process variables affect the removal of turbidity by coagulation/ flocculation? questions coagulation/ flocculation work?

TLA 6: Study treatment step coagulation/flocculation. Students study an article about treatment step of coagulation/flocculation. This article describes the way the treatment is conducted. It also illuminates the difficulties in removing the small clay particles and colloids causing turbidity.

- Students make a summary. They realise that they need to identify all process variables that effect coagulation/flocculation.

\section{TLA 7: Identify process variables tha} process variables and hypothesise about their possible influence. Students use the acquired knowledge in TLA 3 (demonstration) and TLA 6 (article on coagulation/flocculation).

- Students identify multiple process variables that influence the end turbidity, such as dose coagulant, starting turbidity, temperature and mixing effects.

TLA 8: Extend the list of identified process variables. The teacher gives a short lecture about the chemistry underpinning coagulation processes. Next, students study an article from which they learn about coagulation mechanisms and extend their list of process variables.

- Students add process variables acidity $(p H)$ and total salt concentration. Students realise that the influence of the process variables needs to be examined experimentally.

TLA 9: Bring up to date list of concepts and factsheet. Students bring up to date their factsheet (TLA 5) and their list of content related concepts.

- Students realise that it is important to update their newly acquired knowledge and findings regularly.

TLA 10: Investigate the influence of process variables empirically. The teacher divides the work such that three process variables are studied experimentally: dose coagulant $\left(\mathrm{FeCl}_{3}\right)$, starting turbidity and temperature. Students receive laboratory prescripts for the experiments.

- Students understand that everybody needs to conduct the experiments in a similar way in order to combine the results later on.

TLA 11: Draw scatter plots. Students plot scatter diagrams showing the experimental results of end turbidity versus (1) dose coagulant, (2) starting turbidity and (3) temperature. Students interpret the results and think back and forth between the hypothesised influence (TLA $7 \& 8$ ) and observations.

How accurate are the measurements?
TLA 12: Reflect on obtained results. Students evaluate the obtained experimental results.

- Students find out that some experimental results are suspect, due to poor performance or being deviant from the observed tendency, and reflect on possible explanations.

TLA 13: Bring up to date list of concepts and factsheet. Students bring up to date their factsheet (TLA 5) and their list of content related concepts.

- Students realise that it is important to update their newly acquired knowledge and findings regularly.

Which process variables significantly influence the turbidity?

TLA 14: Correlation between end turbidity and process variables. Students present their scatter diagram summarising their results. The teacher invokes discussion about the observed correlations. Students select the process variables with a significant effect on turbidity removal (leaving starting turbidity and dose coagulant). Students study a manual dealing with correlation (and regression).

- Students realise that the experimental results need to be analysed further in order to quantify this influence.

How to quantify

TLA 15: Single regression of end turbidity on dose coagulant and starting turbidity. The the influence of the process variables? teacher gives a short lecture about regression. Next, students perform single regression on end turbidity versus (1) dose coagulant and (2) starting turbidity. Students fit linear and non-linear (power) regression models and reflect on their 'goodness of fit'. Students work according to a manual dealing with correlation and regression, and use MS Excel software.

- Students realise that one model is needed to account for different influences on the same process simultaneously. 
How to couple the models to one formula?
TLA 16: Multiple regression. Students attend a short lecture about multiple regression. Next, students fit multiple linear and non-linear (power) regression models to the data, according to planned procedure using MS Excel. Students evaluate the resulting regression model on aspects 'goodness of fit' and 'validity'.

TLA 17: Bring up to date list of concepts and factsheet. Students bring up to date their factsheet (TLA 5) and their list of content related concepts.

- Students realise that it is important to update their newly acquired knowledge and findings regularly.

Phase IV: Evaluate and reflect on the findings.

\begin{tabular}{|c|c|}
\hline $\begin{array}{l}\text { Content related } \\
\text { questions }\end{array}$ & Sequence of teaching-learning activities (TLA) including desired learning outcomes \\
\hline $\begin{array}{l}\text { In what way can } \\
\text { the model } \\
\text { contribute to } \\
\text { turbidity removal } \\
\text { by coagulation \& } \\
\text { flocculation? }\end{array}$ & $\begin{array}{l}\text { TLA 18: Apply developed multiple regression model. Students apply the multiple regression } \\
\text { model (TLA 16) to calculate the dosage of coagulant needed to produce clear water in a } \\
\text { production side given a certain raw water quality. Students evaluate the outcomes on the aspects } \\
\text { 'purpose', 'reliability' and 'validity'. } \\
\text { - Students realise that their recommendations should be underpinned by reporting the main } \\
\text { findings. }\end{array}$ \\
\hline $\begin{array}{l}\text { What are the } \\
\text { strengths and } \\
\text { weaknesses of the } \\
\text { applied 'black- } \\
\text { box' modelling } \\
\text { approach? }\end{array}$ & $\begin{array}{l}\text { TLA 19: Reflect on the applied 'black-box' modelling approach. The conceptualised input- } \\
\text { output system (TLA 3) is recalled. Students compare the applied black-box modelling approach } \\
\text { with the mechanistic approach and think of pros and cons. In addition, students think over } \\
\text { future research on turbidity removal by coagulation/flocculation based on their own experiences } \\
\text { and extended knowledge. } \\
\text { - Students realise that this type of modelling is an exemplary example of process modelling, } \\
\text { and thus is worthwhile to make explicit. }\end{array}$ \\
\hline
\end{tabular}

Phase V: Express the findings

\begin{tabular}{|l|l|}
\hline $\begin{array}{l}\text { Content related } \\
\text { questions }\end{array}$ & Sequence of teaching-learning activities (TLAs) including desired learning outcomes \\
\hline & $\begin{array}{l}\text { TLA 20: Write a factsheet 'Modelling turbidity removal by coagulation/flocculation'. } \\
\text { Students write a factsheet summarising the applied modelling procedure, main findings, } \\
\text { conclusions and advice for future work. This factsheet is assessed by the teacher. } \\
\bullet \quad \text { Students make their learned knowledge explicit. }\end{array}$ \\
\hline
\end{tabular}




\section{Appendix B. Frame of reference}

The frame of reference describes the expected students' epistemic notions as a result of the strategic components. The epistemic notions are concretised completions of the intended pedagogic effects. The strategy components are operationalised in teaching-learning activities, which are used as data sources.

\begin{tabular}{|c|c|c|}
\hline Strateg|y component & $\begin{array}{l}\text { Data sources } \\
\text { (Learning phase I } \\
\text { Teaching-learning } \\
\text { activity-TLA) }\end{array}$ & Students' epistemic notions \\
\hline $\begin{array}{l}\text { A Visualise and conceptualise for } \\
\text { students the example problem on } \\
\text { which they are going to work: } \\
\text { - demonstrate treatment step } \\
\text { coagulation/flocculation } \\
\text { - conceptualise the modelling } \\
\text { problem as an input-output system }\end{array}$ & I I TLA 3 & $\begin{array}{l}\text { - Identify process variables dose coagulant, starting turbidity and } \\
\text { stirring regime } \\
\text { - Think of measurements to take to prevent occasional outruns } \\
\text { of the norm } \\
\text { - Formulate a rudimentary modelling procedure for input-output } \\
\text { systems }\end{array}$ \\
\hline $\begin{array}{l}\text { B Supply students with a worked-out } \\
\text { analogous modelling problem as } \\
\text { leading example: } \\
\text { - factsheet 'modelling removal of } \\
\text { trichloromethane by activated } \\
\text { carbon filtration' }\end{array}$ & II I TLA 5 & $\begin{array}{l}\text { - Formulate a modelling procedure for the example problem } \\
\text { 1. Study coagulation/flocculation } \\
\text { 2. Identify process variables and describe influence } \\
\text { 3. Conduct experiments } \\
\text { 4. Present data in scatter plots } \\
\text { 5. Develop mathematical model to quantify influence } \\
\text { 6. Evaluate and reflect on the constructed model } \\
\text { 7. Write a factsheet } \\
\text { - Identify advanced model features (goodness of fit, reliability, } \\
\text { validity) to evaluate the developed models }\end{array}$ \\
\hline $\begin{array}{l}\text { C Involve students in a series of } \\
\text { teaching-learning activities } \\
\text { emphasising the nature, } \\
\text { characteristics and wording of the } \\
\text { model(s) at hand: } \\
\text { - perform experiments } \\
\text { - construct scatter plots } \\
\text { - analyse and typify correlations } \\
\text { - perform single and multiple } \\
\text { regression }\end{array}$ & $\begin{array}{l}\text { III I TLA } 14-16 \\
\text { Factsheet }\end{array}$ & $\begin{array}{l}\text { - Conduct experiments according to prescripts (see the point of } \\
\text { collecting much data for each process variable) } \\
\text { - Draw scatter plots and delete suspicious measurements } \\
\text { - Select the process variables with a significant correlation } \\
\text { (positive or negative) with the end turbidity } \\
\text { - Conduct single regression (fit linear and power models on the } \\
\text { data) } \\
\text { - Conduct multiple regression (fit additive and multiplicative } \\
\text { models on the data) } \\
\text { - Evaluate the constructed models on the goodness of fit }\end{array}$ \\
\hline $\begin{array}{l}\text { D Let students apply the constructed } \\
\text { model in a real-world setting: } \\
\text { - calculate the dose of coagulant } \\
\text { needed to produce clear water }\end{array}$ & & $\begin{array}{l}\text { - Evaluate the calculated dose coagulant } \\
\text { - Evaluate the predictive value of the constructed model on the } \\
\text { reliability (number and accuracy of the measurements) and } \\
\text { validity (tested range, industrial vs. laboratory setting) }\end{array}$ \\
\hline $\begin{array}{l}\text { E Let students compare different } \\
\text { modelling approaches: } \\
\text { - compare the black-box modelling } \\
\text { approach with the mechanistic } \\
\text { approach }\end{array}$ & $\begin{array}{l}\text { IV | TLA } 18-19 \\
\text { Factsheet }\end{array}$ & $\begin{array}{l}\text { - Identify the black-box modelling approach and reflect on pro } \\
\text { and cons: } \\
\text { - Quick and cheap } \\
\text { - Suitable to describe process behaviour } \\
\text { - No solid mechanistic foundation } \\
\text { - Evaluate the constructed model and formulate future research } \\
\text { - Formulate a generic modelling procedure for input-output } \\
\text { systems }\end{array}$ \\
\hline
\end{tabular}


Figure 1. Conceptualised scheme of an empirical and mechanistic modelling approach. 


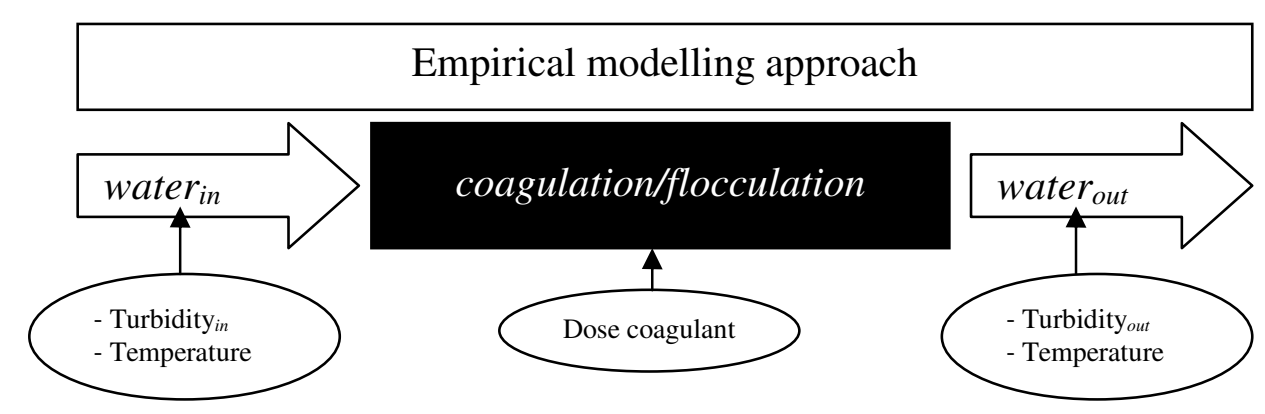

Figure 2. Conceptualised scheme of the empirical modelling approach of turbidity removal by coagulation/flocculation. 


\section{Strategy components}

A Visualise and conceptualise for students the example problem on which they are going to work:

- demonstrate treatment step coagulation/flocculation

- conceptualise the modelling problem as an input-output system

B Supply students with a worked-out analogous modelling problem as leading example:

- factsheet 'modelling trichloromethane removal by activated carbon filtration'

$\mathrm{C}$ Involve students in a series of teaching-learning activities emphasising the nature, characteristics and wording of the model(s) at hand:

- perform experiments

- construct scatter plots

- analyse and typify correlations

- perform single and multiple regression

D Let students apply the constructed model in a realworld setting:

- calculate the dose of coagulant needed to produce clear water

E Let students compare different modelling approaches:

- compare the black-box modelling approach with the mechanistic approach

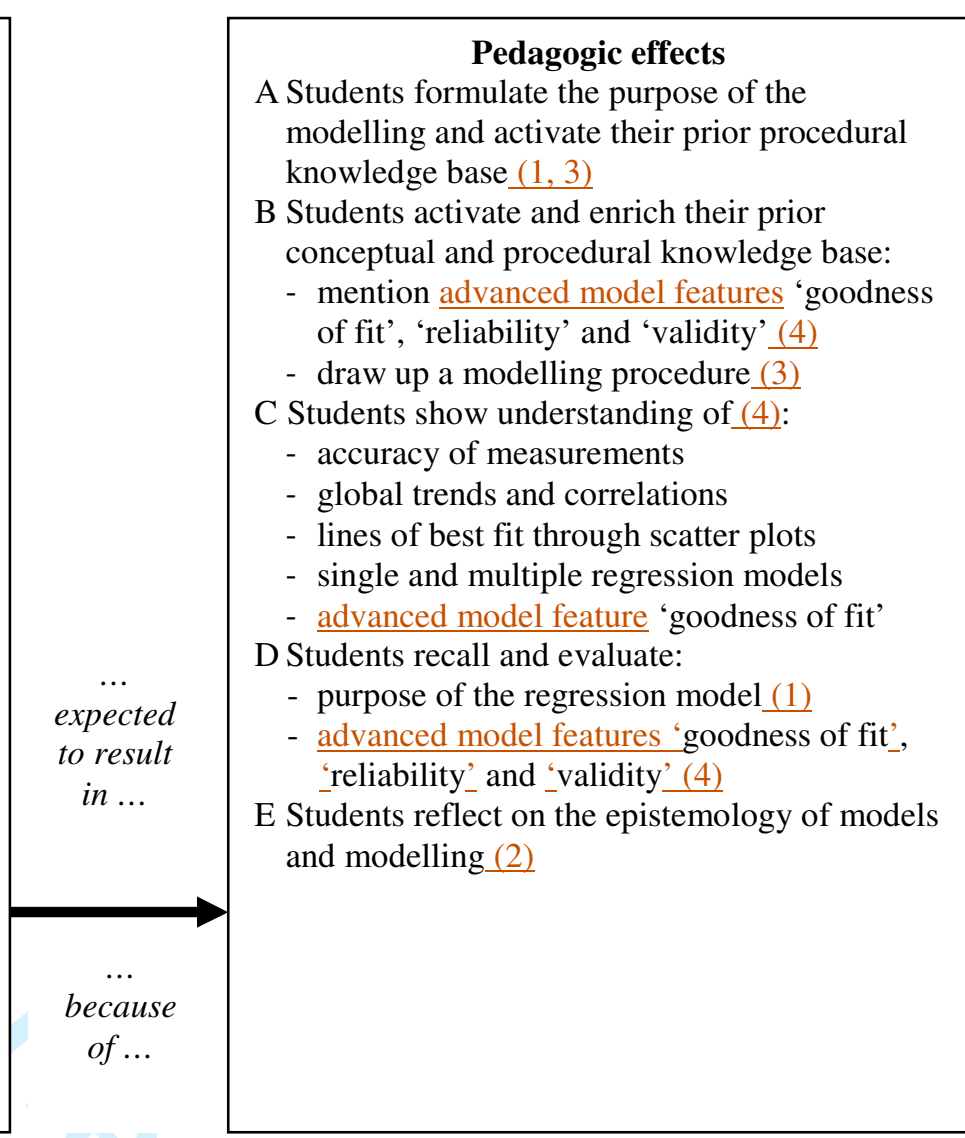

Arguments

A Previous applications of the curriculum unit have proved that visualisation of the modelling problem evokes students' notions concerning a modelling procedure. By conceptualising the modelling problem, students grasp the broader applicability of the modelling procedure to be learned.

B It is found that supplying students with an advanced organiser informs students' views on the activities to conduct and (type of) knowledge to learn/apply. Previous applications of the curriculum unit have revealed that a worked-out analogous modelling problem, originating from the authentic practice at hand, serves as a suitable organiser. It provides students with a view on epistemic notions to take into account.

C It is found that emergent modelling, e.g. gradually formalising empirical data in mathematical models, is a suitable way to guide students through levels of abstraction. Previous enactments of the curriculum unit have revealed that multiple regression should be preceded by single regression to reduce complexity and foster students' understanding.

D Previous applications of the curriculum unit have shown that it is necessary to guide students back to the purpose of the | modelling. The advanced model features goodness of fit, reliability and validity become meaningful to students when evaluating the model outcomes in a real-world setting.

E Previous applications of the curriculum unit have proved that comparing the empirical (black-box) modelling approach with the mechanistic one induces reflection on the pros and cons. Students become aware that multiple modelling approaches exist with different epistemologies. Moreover, students make explicit an empirical (black-box) modelling approach for input-output systems in general.

Figure 3. Conceptualised scheme of the design principle of 'content modelling'. The capital letters connect strategy components with expected pedagogic effects and underlying arguments. The numbers in the 'Pedagogic effects' box refer to the epistemic notions as described in the theoretical framework. 
'... this scatter plot shows that there is little correlation between temperature and the end turbidity. This can be concluded from the low correlation. The process variable temperature has hardly any/no influence on the end turbidity ....'

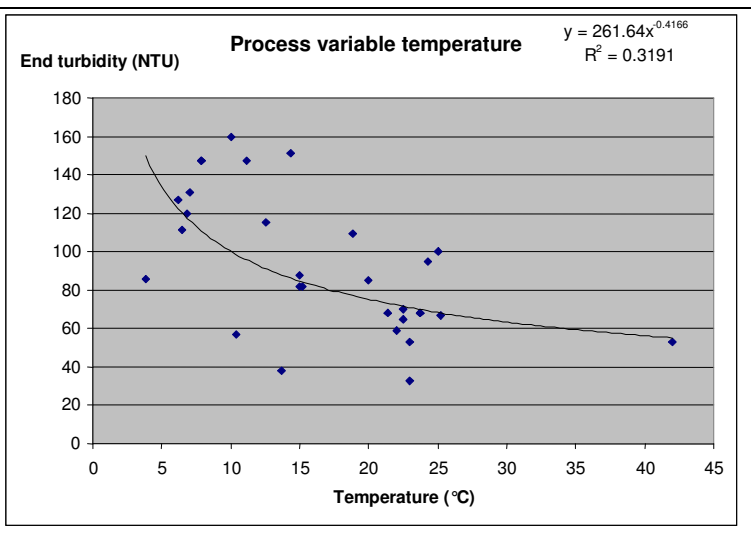

Figure 4. The analysis of student team 1 regarding the type of correlation based on the scatter plot of temperature against end turbidity. 


\section{Strategy components}

A Visualise and conceptualise for students the example problem on which they are going to work:

- demonstrate treatment step coagulation/flocculation

- conceptualise the modelling problem as an input-output system

B Supply students with a worked-out analogous modelling problem as leading example:

- factsheet 'modelling removal of trichloromethane by activated carbon filtration'

C Discuss with students different modelling approaches and point out an appropriate one for the example problem at hand

D Involve students in a series of teachinglearning activities emphasising the nature, characteristics and wording of the model(s) at hand:

- perform experiments

- construct scatter plots

- analyse and typify correlations

- perform single and multiple regression

E Let students apply the constructed model in a real-world setting:

- calculate the dose of coagulant needed to produce clear water

F Let students compare different modelling approaches and reflect on the assumptions and estimations made, and the possible effect of neglected variables:

- compare the black-box modelling approach with the mechanistic approach

\section{Pedagogic effects}

A Students activate their prior conceptual knowledge base and their procedural knowledge base $(1,3)$

B Students make explicit and build on their prior conceptual knowledge base and their procedural knowledge base:

- advanced model features 'goodness of fit', 'reliability' and ‘validity' (4)

- draw up a modelling procedure (3)

C,D Students proceed through the sequence of activities and learn/apply detailed knowledge until a satisfactory solution for the example problem can be presented $(2,4)$ :

- accuracy of measurements

- global trends and correlations

- lines of best-fit through scatter plots

- single and multiple regression models

- advanced model feature 'goodness of fit'

E Students evaluate the learned conceptual and procedural knowledge:

- purpose of the regression model (1)

- advanced model features 'goodness of fit', 'reliability' and ‘validity' (4)

to result

in ...

F Students reflect on the epistemology of models and modelling (2)

\section{Arguments}

A Previous applications of the curriculum unit have proved that visualisation of the modelling problem evokes students' notions concerning a modelling procedure. By conceptualising the modelling problem, students grasp the broader applicability of the modelling procedure to be learned.

B It is found that supplying students with an advanced organiser informs their views on activities to conduct and (type of) knowledge to learn/apply. Application of previous versions of the curriculum unit has revealed that a worked out | analogous modelling problem serves as a suitable organiser. It provides students with a view of the epistemic notions to take into account.

C Previous applications of the curriculum unit have proved that discussing different modelling approaches for the problem at hand fosters reflection on the applied approach in learning phase IV. Students become aware that multiple modelling approaches exist.

D It is found that emergent modelling, e.g., gradually formalising empirical data in mathematical models, is a suitable way to guide students through levels of abstraction.

E Previous applications of the curriculum unit have shown that it is needed to guide students back to the 'purpose of the

| modelling'. The advanced model features goodness of fit, reliability and validity become meaningful to students when evaluating the model outcomes in a real-world setting.

F Previous applications of the curriculum unit have shown that comparing modelling approaches induces reflection on the pros and cons. Students become aware that multiple modelling approaches exist with different epistemologies. Moreover, students make explicit a black-box modelling approach for input-output systems in general.

Figure 5. Conceptualised scheme of a design principle 'content modelling'. The capital letters connect strategy components with expected pedagogic effects and underlying arguments. Alterations to the original filling-in (see Figure 3) are shown in bold. The numbers in the 'Pedagogic effects' box refer to the epistemic notions as described in the theoretical framework. 
Table 1. Broad outline of the content of the five learning phases in the curriculum unit. The placement of the strategy components of the design principle 'content modelling' are highlighted in bold.

\begin{tabular}{|c|c|}
\hline $\begin{array}{l}\text { Learning } \\
\text { Phase }\end{array}$ & Description of the learning phase \\
\hline $\begin{array}{l}\text { I: } \\
\text { Orientate } \\
\text { on the } \\
\text { practice }\end{array}$ & $\begin{array}{l}\text { The first phase induces among students a motive for studying the problems posed in the } \\
\text { practice at hand, and provides them with a sense of direction concerning where their study will } \\
\text { lead them. Firstly, students orientate on the treatment of ground- and surface water for } \\
\text { production of drinking water. Secondly, students take notice of occasional exceeding of } \\
\text { (chemical) parameters, including the turbidity. Thirdly, the removal of turbidity by } \\
\text { coagulation/flocculation is demonstrated by an experiment in class. Students formulate a } \\
\text { purpose of modelling and a (rudimentary) modelling procedure for turbidity removal by } \\
\text { coagulation/flocculation [Strategy component A]. Fourthly, students compare their } \\
\text { formulated modelling procedure with the modelling procedure proposed by experts, by } \\
\text { studying an adapted and shortened version of an authentic project plan 'Modelling drinking } \\
\text { water treatment'. }\end{array}$ \\
\hline $\begin{array}{l}\text { II: } \\
\text { Zoom in } \\
\text { on an } \\
\text { example } \\
\text { problem }\end{array}$ & $\begin{array}{l}\text { In the second phase the students enrich their own formulated modelling procedure. Students } \\
\text { make explicit the sequence of modelling activities to conduct and the advanced model features } \\
\text { to judge the quality of the constructed model(s), and they gain sight of the (type of) end } \\
\text { product to deliver. This process is facilitated by studying a factsheet describing a worked-out } \\
\text { analogous modelling problem, namely modelling the removal of trichloromethane by activated } \\
\text { carbon filtration [Strategy component B]. Students extract the modelling procedure and } \\
\text { identify the advanced model features goodness of fit, reliability and validity. }\end{array}$ \\
\hline $\begin{array}{l}\text { III: } \\
\text { Solve the } \\
\text { example } \\
\text { problem }\end{array}$ & $\begin{array}{l}\text { In the third phase the students extend and apply their knowledge related to modelling turbidity } \\
\text { removal by coagulation/flocculation. This extending and applying of knowledge is an iterative } \\
\text { (intertwined) process. The main stages, as already identified in learning phase II, are: } \\
\text { 1. Identify process variables affecting turbidity removal by coagulation \& flocculation, e.g., } \\
\text { dose of ferric chloride, starting turbidity, temperature, acidity,... } \\
\text { 2. Conduct experiments under controlled conditions to determine the influence of three } \\
\text { process variables, namely dose of ferric chloride, starting turbidity and temperature. } \\
\text { Students work according to laboratory prescripts. } \\
\text { 3. Conduct regression on the acquired empirical data. Students draw scatter plots, select } \\
\text { those process variables with significant correlation, and fit linear and non-linear (power) } \\
\text { regression models to the data. First a single regression, followed by a multiple regression. } \\
\text { Students evaluate the constructed multiple regression model on the advanced model } \\
\text { features goodness of fit, reliability and validity [Strategy component C]. }\end{array}$ \\
\hline $\begin{array}{l}\text { IV: } \\
\text { Evaluate } \\
\text { \& reflect } \\
\text { on the } \\
\text { findings }\end{array}$ & $\begin{array}{l}\text { In the fourth phase students summarise, evaluate and reflect on their findings. Students used } \\
\text { the constructed multiple regression model to calculate the dose of ferric chloride needed to } \\
\text { produce clear water in an industrial plant site [Strategy component D]. They judge the model } \\
\text { outcomes in terms of reliability and validity. Next, students reflect on the applied modelling } \\
\text { approach, as an exemplary case of black-box modelling. They compare the black-box } \\
\text { approach with the mechanistic approach and formulate pros and cons [Strategy component } \\
\text { E]. Finally, students give advice on future research concerning the modelling of turbidity } \\
\text { removal by coagulation/flocculation. }\end{array}$ \\
\hline $\begin{array}{l}\mathrm{V}: \\
\text { Express } \\
\text { the } \\
\text { findings }\end{array}$ & $\begin{array}{l}\text { In the fifth phase the students make explicit their findings in light of the particular modelling } \\
\text { issue worked on. Students write a factsheet (as introduced in learning phase II), summarising } \\
\text { the main results, including an outlook on further research from the students' perspective. }\end{array}$ \\
\hline
\end{tabular}


Table 2. Overview of the realisation (full, partial, low) on each strategy component and major considerations.

\begin{tabular}{|c|c|c|c|c|c|}
\hline \multirow{2}{*}{$\begin{array}{l}\text { Strategy } \\
\text { component }\end{array}$} & \multicolumn{3}{|c|}{ \# student teams } & \multicolumn{2}{|c|}{ Major considerations } \\
\hline & Full & Partial & Low & Successful & $\begin{array}{c}\text { Opportunities and/or possible } \\
\text { improvements }\end{array}$ \\
\hline $\begin{array}{l}\text { A: Visualise and } \\
\text { conceptualise the } \\
\text { example problem }\end{array}$ & 9 & 2 & - & $\begin{array}{l}\text { Students showed } \\
\text { understanding of: } \\
\text { - variability through } \\
\text { external factors } \\
\text { - process variables } \\
\text { - the purpose of modelling } \\
\text { and a rudimentary } \\
\text { modelling procedure }\end{array}$ & $\begin{array}{l}\text { Emphasise the appropriate } \\
\text { modelling approach }\end{array}$ \\
\hline $\begin{array}{l}\text { B: Supply students } \\
\text { with a worked-out } \\
\text { analogous problem }\end{array}$ & 7 & 4 & - & $\begin{array}{l}\text { Students formulated a } \\
\text { modelling procedure }\end{array}$ & $\begin{array}{l}\text { Explicit focus on advanced } \\
\text { model features goodness of } \\
\text { fit, reliability and validity }\end{array}$ \\
\hline $\begin{array}{l}\text { C: Involve students } \\
\text { in the nature, } \\
\text { characteristics and } \\
\text { wording of the } \\
\text { models at hand }\end{array}$ & 4 & 6 & 1 & $\begin{array}{l}\text { Students did show } \\
\text { understanding of: } \\
\text { - correlations between } \\
\text { quantities } \\
\text { - advanced model features } \\
\text { goodness of fit and } \\
\text { reliability }\end{array}$ & $\begin{array}{l}\text { - Notion of significance of } \\
\text { correlation } \\
\text { - Construct a continuous line } \\
\text { of teaching-learning } \\
\text { activities from single to } \\
\text { multiple regression } \\
\text { - Emphasise the advanced } \\
\text { model feature validity }\end{array}$ \\
\hline $\begin{array}{l}\text { D: Let students } \\
\text { apply the } \\
\text { constructed model } \\
\text { in a real-world } \\
\text { setting }\end{array}$ & 6 & 3 & 2 & $\begin{array}{l}\text { Students were aware of: } \\
\text { - considerations regarding } \\
\text { predictive value of model } \\
\text { - the number and accuracy } \\
\text { of the empirical } \\
\text { measurements }\end{array}$ & $\begin{array}{l}\text { - Notion that the model needs } \\
\text { extensive testing in } \\
\text { industrial environment }\end{array}$ \\
\hline $\begin{array}{l}\text { E: Let students } \\
\text { compare different } \\
\text { modelling } \\
\text { approaches }\end{array}$ & 6 & 4 & 1 & $\begin{array}{l}\text { Students evaluated: } \\
\text { - applied empirical } \\
\text { modelling approach }\end{array}$ & $\begin{array}{l}\text { - Make explicit learned 'meta } \\
\text { knowledge' regarding black- } \\
\text { box modelling. } \\
\text { - Reflect on the applied } \\
\text { modelling approach and } \\
\text { make explicit broader } \\
\text { applicability }\end{array}$ \\
\hline
\end{tabular}

